\title{
LA RESPONSABILIDAD CIVIL DEL AGENTE DE SEGUROS
}

\section{THE INSURANCE AGENT'S LIABILITY}

\author{
JUAN BATALLER-GRAU* \\ Fecha de recepción: 18 de junio 2020 \\ Fecha de aceptación 30 de julio 2020 \\ Disponible en línea: 30 de diciembre 2020
}

Para citar este artículo/To cite this article

BATALler GRAU, Juan. La responsabilidad civil del agente de seguros, 53 Rev.Ibero-Latinoam.

Seguros, 85-116 (2020). https://doi.org/10.11144/Javeriana.ris53.rcas

doi:10.11144/Javeriana.ris53.rcas

\footnotetext{
* Este artículo ha sido financiado por CGPA Europe, y forma parte de su contribución para el estudio, análisis, prevención y protección de los riesgos derivados de la actividad profesional de los distribuidores de seguros de Europa. Asimismo, se inserta en el marco de los proyectos del MINISTERIO DE CIENCIA, INNOVACIÓN Y UNIVERSIDADES cuyo título es "El Derecho del seguro en la sociedad del bienestar del s.XXI: la persona como elemento central" con referencia RTI2018-097087-B-I00 y de la GENARALITAT VALENCIANA titulado "Hacia una protección del cliente más global" con referencia AICO/2019/075. Finalmente, quiero agradecer a $\mathrm{M}^{\mathrm{a}}$ Luisa Atienza y a Rafael Marimón las sugerencias y conversaciones mantenidas sobre la materia que, sin duda, han enriquecido este trabajo.

** Catedrático de Derecho mercantil, Universitat de Valéncia (España). Contacto: juan.bataller@uv.es; ORCID: https://orcid.org/0000-0002-1280-7480.
} 


\section{RESUMEN}

La responsabilidad civil profesional del agente ha sido resuelta por el legislador por una lacónica norma de la que es dable extraer dos consecuencias: el régimen jurídico aplicable no es el mismo para agentes exclusivos y vinculados que para operadores de banca seguros; y la previsión del legislador se limita a imputar esta responsabilidad civil al asegurador cuando de agente exclusivo o vinculado se trate. Esta escueta regulación deja muchas cuestiones abiertas lo que obliga a analizar los diferentes elementos de cualquier responsabilidad civil a la luz de la nueva regulación.

Palabras clave: Distribución de seguros, agente de seguros, responsabilidad civil profesional.

\section{ABSTRACT}

Spanish legislator has settled the agent's professional liability by a laconic norm from which two conclusions could be drawn: the legal regime applicable is not the same for exclusive and linked agents as for banking-insurance; and legislator's stipulation is just impute this liability to the insurer when acts as an exclusive or linked agent. This concise regulation leaves many questions opened, which forces to analyze the different elements of any liability in the light of the new regulation.

Key Words: Insurance distribution, insurance agent, professional liability.

\section{SUMARIO}

I.- Introducción; II.- El agente de seguros; 1.- El agente de seguros como mediador de seguros; 2.- El agente de seguros es un empresario mercantil; 3.La especial actividad del agente de seguros; III.- La legitimación pasiva; 1.- El agente de seguros; 1.1.- El agente de seguros como obligado principal; 1.2.- La responsabilidad civil por actos de sus dependientes; 1.3.- La responsabilidad civil por actos de sus colaboradores externos; 2.- La imputación de responsabilidad a la aseguradora; 2.1.- Sobre la imperatividad de la norma; 2.2.- El elemento subjetivo; 2.3.- El ámbito objetivo; 2.4.- La naturaleza jurídica de la responsabilidad del asegurador; 2.5.- El régimen aplicable a los operadores de banca-seguro; A) Una responsabilidad civil vicaria; B) Una responsabilidad civil directa; C) El derecho de repetición del asegurador; IV.La legitimación activa: la naturaleza de la responsabilidad civil profesional; 1.- El asegurador; 2.- El cliente, el tomador y el asegurado; 2.1. Información y asesoramiento en la distribución de seguros; 2.2. - Las dificultades de su calificación como responsabilidad civil extracontractual; 2.3. - Las dificultades de su calificación como responsabilidad civil contractual; 2.4. - Recapitulación crítica; V.- La culpa; VI. - El daño; VII. - El nexo de causalidad; VIII. - La desconcertante disposición transitoria $3^{a}$ del RDLey $N^{\circ} 3 / 2020$; Bibliografía. 


\section{I.- INTRODUCCIÓN}

El Real Decreto-Ley $N^{\circ} 3 / 2020$, de 4 de febrero, de medidas urgentes por el que se incorporan al ordenamiento jurídico español diversas directivas de la Unión Europea en el ámbito de la contratación pública en determinados sectores; de seguros privados; de planes y fondos de pensiones; del ámbito tributario y de litigios fiscales (en adelante RDLey $\mathrm{N}^{\circ} 3 / 2020$ ) ha supuesto, aunque no solo, la implementación de la Directiva (UE) 2016/97 del Parlamento Europeo y del Consejo, de 20 de enero de 2016, sobre la distribución de seguros (en adelante DDS).

La citada DDS, como es sabido ${ }^{1}$, presenta como elemento vertebrador la ampliación del ámbito subjetivo, trasladándose desde la mera mediación -tal y como se venía haciendo en las regulaciones anteriores- hasta una compresión holística de la distribución en los seguros privados. Se incorporan así nuevos sujetos al ámbito subjetivo de la ley en aras a alcanzar una preconizada equidad regulatoria entre los diferentes canales de distribución.

Sin pretender ser exhaustivos en esta modesta introducción se vislumbra una clara dicotomía en el ánimo del legislador español al afrontar la reforma: se aprecia una notable preocupación por la normativa de intervención, lo que contrasta vivamente con el escaso interés por las cuestiones propias del Derecho privado. No hubiera sido inapropiado titular la norma como Ley de ordenación y supervisión de la distribución en seguros privados por las significativas omisiones que presenta en el ámbito de la contratación mercantil. Estas omisiones, por tanto, deberán ser resueltas por el intérprete, con la consiguiente merma de la seguridad jurídica. Más aún en una materia, la distribución en seguros privados, donde tampoco contamos con demasiados trabajos doctrinales que puedan marcar la senda a seguir por los operadores.

El presente trabajo se adentra en la regulación de la figura del agente de seguros, en particular en su responsabilidad civil. Tras unas breves líneas sobre la figura del agente de seguros para enmarcar las coordenadas del régimen jurídico, nos adentraremos en los diferentes elementos que conforman su responsabilidad civil, adoptando aquí un esquema que podríamos adjetivar como clásico, pero necesario en aras a ser exhaustivos respecto de cada uno de sus elementos.

\section{II.- EL AGENTE DE SEGUROS}

\section{1.- El agente de seguros como mediador de seguros}

La nueva regulación ciertamente introduce nuevos sujetos dentro de su ámbito subjetivo, pero mantiene básicamente la misma clasificación entre los mediadores de seguros que ya contenía la Ley N²6/2006, de 17 de julio, de Mediación de Seguros

\footnotetext{
1 Sobre la Directiva puede consultarse Quintáns EIRAS, M.R. "De la mediación a la distribución de seguros. La nueva Directiva 2016/1997”, Revista General de Derecho Europeo, nº. 39, 2016.
} 
y Reaseguros Privados (en adelante LMSRP)². Siguiendo la tradición existente en el mercado español, los mediadores se clasifican en dos grupos: agentes y corredores (art. 135.1 RDLey $\left.\mathrm{N}^{\circ} 3 / 2020\right)^{3}$. El criterio distintivo entre ambos reside en el grado de independencia, profesionalidad e imparcialidad que ha de tener el corredor frente al agente, que se sitúa dentro de la esfera del asegurador. Son dos formas de mediación incompatibles entre sí, en cuanto a su ejercicio "al mismo tiempo" por las mismas personas físicas y jurídicas, de modo que no se pueden ejercer de manera simultánea por un solo mediador (art. 135.2 RDLey $\left.\mathrm{N}^{\circ} 3 / 2020\right)^{4}$.

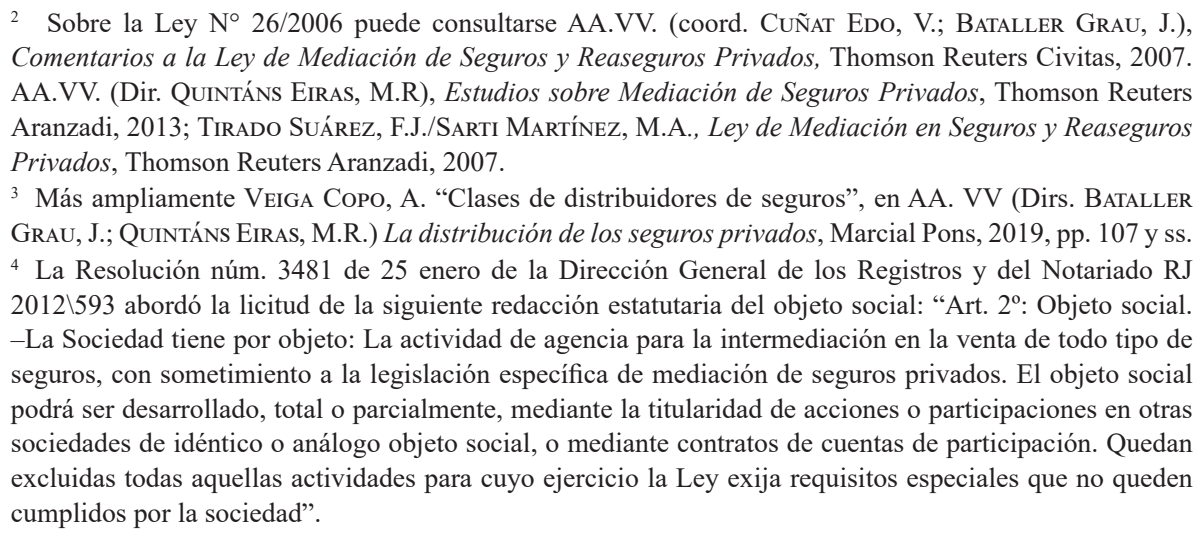
CUARTO.- El 27 de octubre de 2011 tiene entrada en el Registro Mercantil de Toledo recurso interpuesto contra la nota de calificación por el notario para cuyo protocolo se autorizó la escritura de constitución de la sociedad, por el que hace constar que no sólo son incompatibles entre sí -como dice la nota de calificaciónlas actividades de agencia y correduría, sino que también son incompatibles entre sí, dentro de la actividad de agencia, los regímenes exclusivo o vinculado en que ésta puede ejercerse, según resulta de los arts. 19 y 21 de la Ley $N^{\circ}$ 26/2006, de 17 de julio, de mediación de seguros y reaseguros privados. Sin embargo, ninguna de estas incompatibilidades sirve de fundamento a la exigencia por el Registro Mercantil de que se especifique en el objeto social si la entidad va a desarrollar actividades de agencia o de correduría, porque es la propia Ley $\mathrm{N}^{\circ} 26 / 2006$ la que va concretando con toda claridad a lo largo de su articulado, tipo por tipo, qué mediadores de seguros deben hacer dicha especificación en sus estatutos sociales. Tales son los agentes de seguros vinculados (art. 21.3.a) y los corredores de seguros (art. 27.1.a), cuya precisión estatutaria en dicho sentido es requisito previo imprescindible para el ejercicio de tales actividades, y cuya apreciación (de dicha especificación estatutaria) se defiere por los dos preceptos citados a la autoridad encargada del Registro administrativo especial de mediadores de seguros. Por su parte, cuando se trata de agentes de seguros exclusivos, su normativa específica, concretamente los arts. 13 y 15 de la Ley $\mathrm{N}^{\circ}$ 26/2006, no exigen precisión estatutaria del objeto social en tal sentido, a diferencia de lo que sucede en los otros dos supuestos mencionados en el párrafo anterior; bastando, en este último caso, la celebración de un contrato de agencia con una entidad aseguradora y la inscripción en el Registro administrativo especial citado. De modo que, la precisión estatutaria del objeto social en el sentido que dice la escritura rechazada ("la intermediación en la venta de todo tipo de seguros, con sometimiento a la legislación específica de mediación en seguros privados" - art. 2 de los estatutos sociales-) debe considerarse suficientemente precisa a efectos del Registro Mercantil. En resumen, el Registro Mercantil carece de competencia para exigir que las sociedades mediadoras de seguros especifiquen su objeto social más allá de lo que exigen las normas comunes: Porque la apreciación de si se ha incluido en el objeto social la especificación necesaria, en su caso, sobre el modo de ejercicio de la actividad mediadora, compete en exclusiva a la Dirección General de Seguros y Fondos de Pensiones en el momento de despachar la inscripción del mediador de seguros en el Registro administrativo especial. 
El agente de seguros, preceptúa el mismo legislador, es la persona física o jurídica, distinta de una entidad aseguradora o de sus empleados, que mediante la celebración de un contrato de agencia con una o varias entidades aseguradoras, se compromete frente a estas a realizar la actividad de distribución de seguros, en los términos acordados en dicho contrato (art. 140 RDLey $\mathrm{N}^{\circ} 3 / 2020$ ).

La norma define pues la figura del agente en atención a dos elementos: la actividad a desarrollar, la distribución de seguros; y que ésta se hace a partir de la suscripción de un contrato de agencia con la aseguradora.

Seguidamente, el RDLey $\mathrm{N}^{\circ}$ 3/2020 distingue, dentro de los agentes de seguros, entre agentes exclusivos y vinculados, pues en el desempeño de su actividad puede hacerse en régimen de exclusividad, pero también vinculándose con varias entidades aseguradoras.

Así son agentes de seguro exclusivos (art. 147 RDLey N³/20209) los que celebren un contrato de agencia con una única aseguradora, si bien ésta podrá permitir que el agente celebre otro contrato de agencia de seguros distinto con otra entidad aseguradora para operar en determinados ramos de seguros, riesgos o contratos en los que no opere la entidad autorizante. La entidad aseguradora autorizante deberá informar por escrito a la entidad con la cual el agente de seguros pretenda celebrar otro contrato de agencia de los términos en que se otorga la autorización, y procederá a su anotación en el registro de agentes.

Por otro lado, los agentes de seguros vinculados (art. 149 RDLey $N^{\circ} 3 / 20209$ ) son personas físicas o jurídicas que, mediante la celebración de contratos de agencia de seguros con varias entidades aseguradoras y la inscripción en el Registro administrativo especial de mediadores de seguros, corredores de reaseguros y de sus altos cargos, se comprometen frente a éstas a realizar la actividad de mediación de seguros, en los términos acordados en el respectivo contrato de agencia de seguros.

En tercer lugar, los operadores de banca-seguros aparecen cuando las entidades de crédito, los establecimientos financieros de crédito y las sociedades mercantiles controladas o participadas por cualquiera de ellos conforme a lo indicado en el art. 160 RDLey $N^{\circ} 3 / 2020$ se comprometan frente a estas a realizar la actividad de distribución de seguros como agentes de seguros utilizando sus redes de distribución, mediante la celebración de un contrato de agencia de seguros con una o varias entidades aseguradoras (art. 150 RDLey $\mathrm{N}^{\circ} 3 / 2020$ ).

En lo sucesivo, cuando aludamos a agente de seguros incluiremos a las diferentes clases que lo integran, reservando la calificación de agente exclusivo, agente vinculado u operador de banca-seguros cuando apreciemos una especialidad reseñable.

En fin, también hemos de señalar que los agentes de seguros podrán celebrar contratos mercantiles con colaboradores externos ${ }^{5}$ que realicen actividades de distribución por cuenta de dichos mediadores (art. 137 RD Ley $\left.N^{\circ} 3 / 20209\right)^{6}$, sin que exista por tanto restricciones a la utilización de estos colaboradores mercantiles.

\footnotetext{
5 Sobre la cuestión Díaz De La Rosa, A. "Los colaboradores de los distribuidores de seguros en el proyecto de Ley de Distribución de Seguros Privado”, en AA. VV (Dirs. Bataller Grau, J.; Quintáns Eiras, M.R). La distribución de los seguros privados, Marcial Pons, 2019, pp. 149 y ss.

${ }^{6}$ Vid. SAP de Salamanca núm. 181/2015 de 29 junio (Sección 1ª) AC 2015\104.
} 


\section{2.- EL AGENTE DE SEGUROS ES UN EMPRESARIO MERCANTIL}

Aunque pueda parecer una obviedad, comenzaremos resaltando que los agentes de seguro, más allá de la singularidad de la actividad que desarrollan, reciben la calificación de empresario mercantil, bien individual bien social.

El agente de seguros persona física es un empresario mercantil individual al reunir los tres requisitos que impone el Código de comercio español según la interpretación dada por el Tribunal Supremo y la doctrina científica: tienen plena capacidad legal, ejercen habitualmente una actividad mercantil -tanto los seguros como la distribución no hay duda que lo son- y actúan en nombre propio.

Por su lado, el agente de seguros persona jurídica al adoptar la forma de sociedad anónima o limitada adquieren la calificación de empresario mercantil por el mismo tipo social (mercantilidad por la forma, art. 2 de la Ley de sociedades de capital) 7 .

Así las cosas, el agente de seguros en tanto empresario mercantil está sometido al mismo estatuto jurídico que el resto de empresarios mercantiles al que se añaden los deberes específicos que impone la normativa de distribución. Dentro del estatuto jurídico queremos en este momento resaltar que el agente de seguros, en tanto empresario mercantil, asume las consecuencias de su actividad. O, dicho de otro modo, el agente de seguros responde con su patrimonio del cumplimiento de sus obligaciones como cualquier otro empresario mercantil, sin perjuicio de las especialidades que referiremos seguidamente. No conviene pues olvidar que las especialidades prevalecen sobre el derecho común allí donde son incompatibles, pero no empecen la aplicación del resto del régimen jurídico del estatuto jurídico del empresario mercantil.

\section{3.- LA ESPECIAL ACTIVIDAD DEL AGENTE DE SEGUROS}

El agente de seguro es, ante todo, un mediador de seguros, por lo que su ejercicio profesional se inserta dentro de la distribución de seguros. Por tal, hemos de entender toda actividad de asesoramiento, propuesta o realización de trabajo previo a la celebración de un contrato de seguro, de celebración de estos contratos, o de asistencia en la gestión y ejecución de dichos contratos, incluyendo la asistencia en casos de siniestro (art. 129 RDLey N $\mathrm{N}^{\circ}$ /2020).

En particular la actuación del agente de seguros puede concretarse en las siguientes actuaciones:

\footnotetext{
7 Excluiremos de este trabajo a aquellos otros agentes que adquieren la forma de cooperativa por ser una forma poco extendida en la realidad del mercado y el análisis de sus posibles singularidades nos alejaría del elemento central de nuestro análisis.

8 Seguimos en este punto, si bien adaptado a la nueva regulación, el análisis planteado por GónZALEZ CAStilla, F. "El agente de seguros y el operador de banca-seguros", en AA.VV. (coord. Cuñat Edo, V.; Bataller Grau, J.). Comentarios a la Ley de Mediación de Seguros y Reaseguros Privados, Thomson Reuters Civitas, 2007, p. 158.
} 
a) "Presentación, propuesta o realización de trabajos previos a la celebración de un contrato de seguro". Esta mención del art. 129 RDLey $\mathrm{N}^{\circ} 3 / 2020$, suele concretarse en los contratos de agencia, señalando que corresponde al agente la oferta y asesoramiento preparatorio de la formalización de las pólizas, transmitir a la compañía la información recabada de los tomadores, así como hacer llegar a los tomadores la documentación contractual emitida por la compañía.

b) “Celebración de estos contratos". Actividad en la que el agente actúa ante el tomador de seguros creando una apariencia de prolongación de la entidad aseguradora a la que se encuentra vinculado. Incluimos aquí actividades tales como la asistencia en la perfección del contrato, o el proceder al cobro de la primera prima, en caso de que no se haga el pago a través de domiciliación bancaria.

c) "De asistencia en la gestión y ejecución de dichos contratos, incluyendo la asistencia en casos de siniestro". Aquí se incluirían actividades tales como la transmisión de los cobros efectuados y la remisión de los fondos de la compañía que tuviera en calidad de depósito; recibir las reclamaciones de los tomadores, asegurados o beneficiarios y transmitirlas a la compañía; asistir al tomador en relación con las declaraciones de modificación del riesgo; proceder al nombramiento de perito de acuerdo con las instrucciones y listas proporcionadas por la aseguradora; asesorar al tomador en el momento del siniestro (aviso a la compañía, informaciones adicionales en orden al cálculo de los daños); efectuar el pago de los siniestros que se le encomiende por la compañía, etc.

La distribución aparece como una actividad dirigida a un resultado: la formalización del contrato de seguro (si no se produce el resultado no se obtiene, evidentemente, la retribución). Ahora bien, independientemente de la perfección del contrato de seguro, la actividad de distribución se prolonga más allá en el tiempo, durante toda la vida de la vinculación del cliente con la aseguradora (mientras no se extinga, claro está, la relación contractual de agencia).

\section{III.- LA LEGITIMACIÓN PASIVA}

\section{1.- EL AGENTE DE SEGUROS}

\section{1. - El agente de seguros como obligado principal}

Sentado que el agente de seguros es un empresario mercantil singularizado por el ejercicio de una actividad de distribución de seguros que entraña unas funciones singulares sobre las que recaen especiales deberes, estamos en disposición de afirmar que será el principal responsable de sus acciones u omisiones ${ }^{9}$. Todo empresario mercantil

\footnotetext{
9 Considera responsable civil, aun con importantes variaciones respecto de la tesis aquí mantenida, Elguero, J.M. "La responsabilidad civil profesional del agente de seguros", en AA. VV (Dirs. BATALLER Grau, J.; Quintáns EIRAs, M.R). La distribución de los seguros privados, Marcial Pons, 2019, p. 247.
} 
desarrolla la actividad en nombre propio, lo que implica que las consecuencias de su actividad deben recaer sobre su patrimonio. Esta afirmación que pudiera parecer obvia para un mercantilista, quien suscribe no la percibe como pacífica en el mercado asegurador. De ahí la necesidad de fijarla como punto de partida del presente trabajo.

En el presente trabajo nos ocuparemos de su responsabilidad civil en el ejercicio de su actividad de distribución. Orillamos, por consiguiente, el resto de responsabilidades civiles por entender que no presentan especialidades frente a otros empresarios mercantiles. Así sucede, por citar algún ejemplo, con su responsabilidad como locatario de un local abierto al público o con la responsabilidad civil frente a sus trabajadores por prevención de riesgos laborales.

\section{2. - La responsabilidad civil por actos de sus dependientes}

La denominada responsabilidad por hecho ajeno, cuando éste es un ilícito civil, se contempla en el art. $1903 \mathrm{CC}$. Tal denominación pone de relieve que quien ocasiona el daño de forma directa o inmediata no es quien, de acuerdo con el art. 1903 CC, está obligado a repararlo, sino una persona distinta, de la que aquél debe responder. Se suele destacar aquí la relación de subordinación o dependencia que existe entre el autor material del hecho dañoso y el llamado a responder por él.

El precepto fue calificado inicialmente de corte subjetivista, bien por culpa al vigilar, bien por culpa al elegir o dirigir a sus empleados. No obstante, como es sabido, la interpretación jurisprudencial de la norma a través de la inversión de la carga de la prueba y de una exacerbada elevación del canon de diligencia exigible al empresario mercantil inició el camino hacia rasgos más propios de la responsabilidad objetiva.

En el presente caso, el agente en cuento empresario mercantil, responde de sus dependientes. Aquí por tal nos referiremos principalmente a los trabajadores por cuenta ajena que presten sus servicios para el agente de seguros, sea persona física o jurídica, sea exclusivo o vinculado e incluso operador de banca-seguros.

En el caso del agente de seguros se reproduce la estructura propia de la responsabilidad civil por hecho ajeno, en este caso agravada por el posible incumplimiento del dependiente de los deberes legales que impone el RDLey $\mathrm{N}^{\circ} 3 / 2020$. O, dicho de otro modo, a los supuestos habituales de responsabilidad del empresario por actos de sus empleados, se suman en el caso del agente de seguros los posibles incumplimientos de los deberes legales impuestos por la legislación sobre distribución de cuyo cumplimiento se convierte en responsable el agente de seguros.

\section{3. - La responsabilidad civil por actos de sus colaboradores externos}

El art. 137 RDLey regula a los colaboradores externos quienes desarrollan actividades propias de la distribución de seguros privados, pero sin recibir el grado de mediador dado la limitación de funciones que los singularizan. El agente, en cuanto mediador, puede recurrir también a la utilización de auxiliares. 
Por tanto, se reproduce aquí por lo general la misma estructura que en la relación entre asegurador y agente. El colaborador externo se encuentra usualmente vinculado con el agente de seguros a través de un contrato de agencia ${ }^{10}$.

Ahora bien, aquí el precepto regulador es el art. 137.2 RDLey cuyo tenor literal dispone:

"Los colaboradores externos desarrollarán su actividad bajo la dirección, régimen de responsabilidad administrativa, civil profesional, y régimen de capacidad financiera del mediador para el que actúen".

Centrándonos en la responsabilidad civil, el tenor del precepto resulta aún menos preciso desde el punto de vista de técnica jurídica que el texto del art. 143 RDLey que analizaremos seguidamente. La norma se limita a decir que el colaborador externo desempeñara su labor bajo la responsabilidad civil profesional del agente. La utilización de la palabra bajo carece de la más mínima precisión. La intención del legislador es establecer algún tipo de responsabilidad civil del agente respecto de la actuación del colaborador, pero sin calificarla. Por consiguiente, la hermenéutica del precepto requerirá de la paulatina decantación jurisprudencial a medida que se vayan presentando supuestos de hecho que incidan sobre el régimen jurídico ahora analizado Solo así se podrá precisar la responsabilidad civil del colaborador externo a la que estimamos pudieran extrapolarse las mismas consecuencias jurídicas que se deducen del art. 143 RDLey $\mathrm{N}^{\circ}$ 3/2020 por concurrir identidad de razón.

\section{2.- LA IMPUTACIÓN DE RESPONSABILIDAD A LA ASEGURADORA}

El art. 143 RDLey $N^{\circ}$ 3/2020 tiene como epígrafe la responsabilidad civil profesional $^{11}$. Sin embargo, de su lectura se aprecia que no regula íntegramente la responsabilidad civil del agente de seguros en lo atinente a su actividad de distribución, sino que se circunscribe a establecer los sujetos responsables de tal actividad, sin entrar en el resto de elementos que conforman todo régimen de responsabilidad civil (acción u omisión, culpa, daños y nexo de causalidad).

La lectura del precepto provoca múltiples cuestiones tales como la posible derogación contractual de la norma, la extensión subjetiva del precepto, la delimitación de la responsabilidad civil que se imputa a la aseguradora y, cómo no, la naturaleza jurídica de la responsabilidad. Procede pues su análisis por separado.

\footnotetext{
${ }^{10}$ Díaz De La Rosa, A. "Los colaboradores de los distribuidores...", cit., pp. 170 y ss. analiza las diferentes modalidades contractuales que pueden vincular al colaborador con el distribuidor, si bien aquí nos decantamos por centrarnos en el contrato de agencia por estimar es la fórmula más habitual a la luz de nuestra experiencia.

11 Su tenor literal dispone:

"1. Sin perjuicio de la responsabilidad penal o de otra índole en que pudiera incurrir el agente de seguros en el ejercicio de su actividad de distribución de seguros, será imputada a la entidad aseguradora con la que hubiera celebrado un contrato de agencia de seguros la responsabilidad civil profesional derivada de su actuación y de la de sus colaboradores externos, todo ello de conformidad con lo dispuesto en los contratos de agencia celebrados.
}

2. El apartado anterior no será de aplicación a los operadores de banca-seguros". 


\section{1. - Sobre la imperatividad de la norma}

La primera pregunta que debemos responder se centra en la posible imperatividad de la norma. $\mathrm{O}$, dicho de otro modo, si es posible que se pueda modificar el régimen legal establecido en el precepto a través de su modificación en el contrato o contratos de agencia. La norma no resulta especialmente clarificadora en este punto.

A favor de la imperatividad de la norma emerge con fuerza el argumento del respeto a su finalidad, que no es otra que preservar los derechos de los clientes. Efectivamente, si a la habitual fragilidad financiera que presentan los agentes de seguros, añadimos las elevadas indemnizaciones en que pueden incurrir, parece conveniente imputar la responsabilidad civil profesional de los mismos al asegurador en aras a garantizar el efectivo cobro de la indemnización de daños y perjuicios. Téngase en cuenta que el agente de seguros, a diferencia del corredor, no viene obligado a suscribir un seguro de responsabilidad civil profesional (art. 147 para el agente exclusivo y art. 149 para el agente vinculado, ambos del RDLey $\mathrm{N}^{\circ} 3 / 2020$ ). Por tanto, parece prudente extender esta responsabilidad civil a la entidad aseguradora cuya solvencia se trata de garantizar por el legislador a través de la Ley $\mathrm{N}^{\circ}$ 20/2015, de 14 de julio, de ordenación, supervisión y solvencia de las entidades aseguradoras y reaseguradoras. En consecuencia, al ser una norma en interés de tercero parecería razonable defender que estamos ante un precepto imperativo.

Frente a la interpretación teleológica, empero, surge con similar vigor la interpretación literal de la norma que pareciera abrazar una naturaleza dispositiva. Aquí el argumento central se sitúa en el texto final del precepto cuando establece que el régimen de responsabilidad será "de conformidad con lo dispuesto en los contratos de agencia celebrados". Este inciso final, ausente en la anterior regulación contenida en la LMSRP, apunta directamente hacia la posibilidad de modular en sede contractual la imputación de la responsabilidad civil profesional a las aseguradoras.

Un primer impulso pudiera llevarnos a pensar que, al igual que sucede en la Ley de contrato de seguro, el legislador establece un régimen de semimperatividad que actuará de mínimo común denominador en favor del cliente. Sin embargo, esta interpretación se encuentra con el severo obstáculo de que el precepto no restringe esta imputación de responsabilidad a ningún supuesto ni establece atenuantes. La regulación parte de la imputación total.

Otra interpretación que también debiéramos descartar reside en atribuir ese poder modulador de los contratos únicamente a la responsabilidad contractual entre agente y asegurador, pero no es este el ámbito objetivo de la norma. Así, esta interpretación chocaría con la propia literalidad de la norma al carecer de sentido que la aseguradora fuera responsable frente a sí misma en caso de no regular contractualmente la cuestión. Por consiguiente, tampoco parece que ésta deba ser la interpretación a acoger.

Una posible solución pasaría por permitir a la entidad aseguradora eludir su responsabilidad civil obligando contractualmente al agente de seguros a suscribir un seguro de responsabilidad civil. De esta manera se preservarían los intereses en juego permitien- 
do al asegurador optar entre la imputación de la responsabilidad o su externalización, cuestión que quedaría así regulada en los condicionados generales que impone a su red agencial. Solución que tampoco perjudica la posición del cliente quien dispone en cualquiera de las dos posibilidades de un nuevo sujeto a quien exigir la indemnización de daños y perjuicios: en un caso al asegurador para quien distribuye seguros el agente, en el otro el asegurador de la responsabilidad civil. No está de más recordar que en el mercado asegurador hay muchas aseguradoras que no operan en el ramo de responsabilidad civil y pudiera interesarles externalizar este riesgo por carecer de experiencia en su gestión. No obstante, hemos de ser honestos y una cosa es lo que hubiera sido razonable prever en la norma y otra bien distinta la interpretación que es dable extraer a partir del tenor literal del precepto.

En definitiva, estamos ante un tema abierto que requerirá decantación jurisprudencial. Acoger una interpretación literal conduce a afirmar el carácter dispositivo de la norma. Asumir una hermenéutica teleológica implica defender su imperatividad. La jurisprudencia será la que, llegado el momento, pueda dilucidar esta disyuntiva.

\section{2. - E1 elemento subjetivo}

\section{A. El agente de seguros}

La norma comienza incluyendo dentro de su ámbito de aplicación subjetivo a todos los agentes de seguros. Por el contrario, en su segundo número se excluye a los operadores de banca-seguros. A su vez, la norma no distingue entre persona física o jurídica, por lo que se entienden incluidas las dos. Consiguientemente, el precepto se aplica a los agentes de seguros exclusivos, pero también a los vinculados, sean personas físicas o jurídicas tanto cuando actúen directamente ellos como a través de sus colaboradores externos, quedando al margen los operadores de banca-seguros quienes disponen de un régimen diseñado ex profeso para ellos.

\section{B. El asegurador}

En el lado pasivo la responsabilidad se imputa al asegurador con el que se haya celebrado un contrato de agencia. Esta forma de atribución de la responsabilidad civil no plantea mayores problemas cuando el agente exclusivo solo tenga un contrato de agencia, pues toda su actividad y, por ende, su responsabilidad, podemos atribuirla a una única aseguradora.

Ahora bien, la cuestión se complica cuando se trata de un agente exclusivo que esté autorizado a contratar con otra aseguradora que no opere en el concreto ramo o ramos de la entidad principal. Estas dudas se multiplican cuando el agente de seguros sea vinculado, dado que per se estamos ante un mediador que ha perfeccionado diferentes contratos de agencia. La imputación ya no se nos presenta aquí como una obviedad. 
El comportamiento del agente exclusivo autorizado y a mayor abundamiento el agente vinculado puede individualizarse en un concreto contrato, pero en ocasiones no será posible.

A nuestro juicio, si el comportamiento no es individualizable y, por tanto, imputable directamente a la relación que mantiene con una concreta aseguradora, la responsabilidad de todas ellas será solidaria. Ante la imposibilidad de imputar el comportamiento a una sola aseguradora, el carácter mercantil de la actividad y el principio de protección del cliente que subyace en la redacción de la norma son los motivos que inspiran nuestra opinión.

Más dudas nos surgen en aquellos supuestos en que la acción u omisión pueda individualizarse respecto de una concreta aseguradora. La cuestión a resolver reside en determinar si es dable una extensión del régimen de responsabilidad solidaria a todas las aseguradoras en aras a la protección de la víctima o si, por el contrario, prima una concepción más restrictiva que limite la responsabilidad únicamente a la aseguradora vinculada el comportamiento. Nuestro impulso es inclinarnos por la primera interpretación, aun cuando estamos nuevamente ante una cuestión abierta.

\section{3. - El ámbito objetivo}

\section{A. La responsabilidad penal}

La norma comienza excluyendo de su ámbito de aplicación la responsabilidad penal. Con esta exclusión el legislador quiere señalar que ésta existe ("sin perjuicio...") para los agentes de seguros, tanto con relación a los delitos en que éstos pueden incurrir como consecuencia del ejercicio de su actividad, como por supuesto con respecto a los ajenos a la misma. Efectivamente, el delito puede ser ajeno al estricto desarrollo profesional, pero cometerse durante su desempeño (p. ej. si el agente de seguros agrede a un tomador o asegurado durante una visita). En este último caso, se aplicará sin más la legislación penal.

Centrándonos en la primera, el agente puede incurrir en responsabilidad penal tanto frente al asegurador; como frente al tomador y el asegurado; e incluso frente a otros terceros en el desempeño de su actividad de distribución. Pues bien, esta responsabilidad penal, cuando exista, no podrá ser imputada al asegurador, según dispone el legislador en el precepto ahora analizado. En conclusión, la responsabilidad penal es directa y personal del agente. Las penas, en definitiva, no pueden trasladarse ${ }^{12}$.

Asimismo, debemos señalar la posibilidad que la responsabilidad penal sea imputada directamente a la persona jurídica, consagrada en el artículo 31 bis CP, tras las reformas de 2010 y 2015. Este precepto establece la responsabilidad penal de la persona jurídica para un numerus clausus de delitos, entre los que se encuentran los de estafa

${ }_{12}$ Elguero, J.M. La responsabilidad civil profesional..., cit., p. 246. 
(arts. 248 y 251 bis CP) o la revelación de secretos (arts. 197 y 197 quinquies CP), encuadrables todos ellos en la actividad del agente de seguros persona jurídica ${ }^{13}$.

Además de la pena, el delito acarrea una responsabilidad civil extracontractual. Surge entonces la cuestión relativa a si la extensión de la responsabilidad al asegurador abarca también la responsabilidad civil ex delicto. A partir de aquí es donde empiezan a aparecer las dudas.

Una primera interpretación consiste en entender que el precepto al eludir la responsabilidad penal no distingue entre ninguna de sus consecuencias. El agente de seguros que delinque debe asumir personalmente las penas, así como la posible responsabilidad civil que derive de los daños ocasionados. Se dota así de una mayor significación al precepto analizado, pues la mera exclusión de la responsabilidad puramente penal parece evidente dada la naturaleza de la misma.

Por el contrario, se puede defender la imputación a la aseguradora de la responsabilidad civil derivada del delito basándonos en la preconizada unidad de la responsabilidad civil. La concurrencia de un delito, se afirmaría, no modificaría la estructura propia de los elementos de la responsabilidad civil.

Nos encontramos pues ante una nueva duda que requerirá de la consiguiente decantación jurisprudencial. Asumir la primera tesis concede a la mención del legislador un contenido, mientras que decantarnos por la segunda proporciona un mejor encaje dogmático. Nosotros nos inclinamos por abrazar la primera, pero sin negar la virtualidad de la segunda.

\section{B. Responsabilidad de otra indole}

El precepto, de una manera no exenta de ambigüedad, excluye además de la responsabilidad penal aquellas que sean "de otra índole". Surge entonces la necesidad de interpretar que responsabilidades debemos incluir en este concepto jurídico indeterminado.

A nuestro juicio, no plantea dudas extender la exclusión a aquellas responsabilidades que provengan del Derecho administrativo sancionador por reunir las mimas notas que el Derecho penal. Por tanto, las sanciones administrativas que provengan de la misma aplicación del RDLey $\mathrm{N}^{\circ}$ 3/2020 quedan allende el ámbito de aplicación del precepto $^{14}$. Pero no solo, pues aquí es dable incardinar también otros regímenes jurídicos propios del Derecho administrativo sancionador que vinculan al agente de seguros tales como la protección de datos, la normativa fiscal, o la propia de la Seguridad social, por citar algunas. En definitiva, las sanciones administrativas serán impuestas directamente al agente de seguros, sin que puedan imputarse a la aseguradora.

Ahora bien, no resulta tan pacífico precisar si las responsabilidades "de otra índole" es dable extenderlas más allá del mero Derecho administrativo sancionador. Nos refe-

13 Elguero, J.M. La responsabilidad civil profesional..., cit., p. 247.

14 La responsabilidad administrativa relativa a la actividad de distribución de los agentes de los agentes de seguros se encuentra regulada en el art. 191 RDLey $\mathrm{N}^{\circ} 3 / 2020$. 
rimos aquí a la responsabilidad civil que excede del estricto desarrollo de su actividad de distribución de seguros. Parece evidente que si de la vivienda particular del agente persona física cae una maceta causando lesiones a un viandante nada tiene que imputarse al asegurador.

Ahora bien, la cuestión suscita más interrogantes en la práctica si la maceta cae desde la oficina en la que desarrolla su actividad o si atropella a un peatón con motivo de un desplazamiento profesional. Igual sucede, por citar otro ejemplo, cuando el agente de seguros recibe a un cliente, potencial o efectivo, en su despacho profesional. Si durante la mera visita se producen daños al cliente, sean daños personales o materiales, dichos daños no serán consecuencia de una actividad profesional en sentido estricto $\mathrm{y}$, por tanto, no deberían ser calificados de responsabilidad civil profesional.

A nuestro entender debe quedar excluida la responsabilidad civil que surja con ocasión de esa relación profesional, encontrándonos entonces fuera del ámbito de aplicación de la norma ${ }^{15}$. Aquí es donde encuentra pleno sentido la exclusión de las responsabilidades de "de otra índole". Desde un punto de vista teleológico tiene pleno sentido imputar la responsabilidad civil del agente de seguros a la entidad aseguradora cuando sea la derivada de su actividad de distribución de seguros privados. Ahora bien, extender ésta más allá cuando estamos hablando de un empresario mercantil, no encuentra fácil justificación.

\section{La responsabilidad civil profesional}

Tras lo expuesto resulta palmario que la responsabilidad civil profesional es el elemento central para determinar el ámbito de aplicación objetivo del art. 143 RDLey $\mathrm{N}^{\circ} 3 / 2020$. Su delimitación permite imputar o no la responsabilidad al asegurador. $\mathrm{O}$, dicho de otro modo, si la responsabilidad civil es profesional, estaremos dentro de su ámbito de aplicación; mientras si no lo es, nos situamos fuera de su eficacia.

La delimitación del concepto debe partir, por tanto, del término "profesional". Como ya hemos adelantado, uno de los elementos definidores del agente de seguros reside precisamente en la actividad que desarrolla: la distribución de seguros privados. Además, su actividad no se limita a la fase de suscripción del contrato de seguro, sino que se prolonga a lo largo de la vigencia del mismo. Por consiguiente, el único criterio delimitador de esta responsabilidad civil reside pues en circunscribirse a una estricta actividad de distribución, tal y como la conceptúa el art. 129 RDLey $N^{\circ} 3 / 2020^{16}$.

\footnotetext{
15 Elguero, J.M. "La responsabilidad civil profesional ..., cit., p. 248.

16 Art. 129 RDLey $N^{\circ}$ 3/2020 incluye (sentido positivo): "toda actividad de asesoramiento, propuesta o realización de trabajo previo a la celebración de un contrato de seguro, de celebración de estos contratos, o de asistencia en la gestión y ejecución de dichos contratos, incluyendo la asistencia en casos de siniestro. También se entenderán incluidas la aportación de información relativa a uno o varios contratos de seguro de acuerdo con los criterios elegidos por los clientes a través de un sitio web o de otros medios, y la elaboración de una clasificación de productos de seguro, incluidos precios y comparaciones de productos, o un descuento sobre el precio del seguro, cuando el cliente pueda celebrar el contrato de seguro directa o
} 


\section{4. - La naturaleza juridica de la responsabilidad del asegurador}

\section{A. Una responsabilidad civil vicaria}

Una de las cuestiones centrales a dilucidar en la interpretación del precepto reside en determinar cuál es la responsabilidad que atribuye a las entidades de seguros. El precepto, de nuevo, dista de ser lo preciso que debiera. Su tenor literal se limita a decir que la responsabilidad civil profesional del agente "será imputada" a la entidad aseguradora.

Conviene comenzar recordando que el agente es un empresario mercantil bien social bien individual, por lo que el precepto no pretende en ningún caso excluirlo del círculo de responsables civiles. El agente de seguros mantiene incólume su responsabilidad civil profesional frente a los tomadores, asegurados y beneficiarios. Ser empresario mercantil determina que ejerce la actividad asumiendo directamente los riesgos que entraña. La norma no contiene mención alguna que permita exonerar al agente de seguros de esta responsabilidad civil profesional, lo que por otro lado sería extravagante dentro del Derecho español al convertir en inimputable a un empresario mercantil que recibe un lucro en el desarrollo de una actividad mercantil sin asumir el correlato de su desempeño profesional en el mercado.

Por consiguiente, la función de la norma reside en extender el círculo de responsables para incluir también al asegurador. En consecuencia, a la responsabilidad propia del agente de seguros se suma ahora en virtud del precepto analizado un nuevo sujeto que responderá por el desempeño profesional de sus agentes: el asegurador.

El precepto pudiera parecer una reiteración de la responsabilidad por hecho ajeno, regulada con carácter general en el art. 1903 del Código civil ${ }^{17}$. Estaríamos aquí ante la responsabilidad civil del empresario por los hechos de sus dependientes contenida en el párrafo 4 del citado art. 1903 CC. Sin embargo, nos parece dudoso que entre un agente de seguros y una entidad aseguradora pueda hablarse de que exista una rela-

\footnotetext{
indirectamente utilizando un sitio web u otros medios". Y excluye (sentido negativo):

a) Las actividades de información prestadas con carácter accesorio en el contexto de otra actividad profesional:

1. ${ }^{\circ}$ si el proveedor no efectúa ninguna acción adicional para ayudar a celebrar o a ejecutar un contrato de seguro;

2. ${ }^{\circ}$ si la finalidad de esa actividad no consiste en ayudar al cliente en la celebración o ejecución de algún contrato de reaseguro.

b) La gestión de siniestros de una entidad aseguradora o reaseguradora, a título profesional, y el peritaje y la liquidación de siniestros.

c) El mero suministro de datos y de información sobre tomadores potenciales a los mediadores de seguros o reaseguros, o a las entidades aseguradoras o reaseguradoras, si el proveedor no efectúa ninguna acción adicional para ayudar a celebrar un contrato de seguro o de reaseguro.

d) El mero suministro de información sobre productos de seguro o reaseguro, sobre un mediador de seguros o reaseguros, o sobre una entidad aseguradora o reaseguradora a tomadores potenciales, si el proveedor no efectúa ninguna acción adicional para ayudar a celebrar un contrato de seguro o de reaseguro.

e) La actuación de las entidades aseguradoras como abridoras en las operaciones de coaseguro.

17 Así parece calificarla Elguero, J.M. La responsabilidad civil profesional ..., cit., pp. 246 y 249.
} 
ción de dependencia, tal y como es calificada en el ámbito del art. 1903 CC. La doctrina identifica cuatro elementos que deben apreciarse en la relación entre el empresario y el causante del daño ${ }^{18}: 1^{\circ}$ ) el causante del daño debe desempeñar la actividad por cuenta o en interés del empresario; $2^{\circ}$ ) debe tratarse de una relación de naturaleza jurídica, no siendo suficiente un mero sometimiento económico; $3^{\circ}$ ) en el desempeño de la actividad el causante del daño ha de estar sometido a las instrucciones o supervisión del empresario; $4^{\circ}$ ) la actuación del dependiente debe producirse dentro de las funciones que tiene encomendadas.

Pocas dudas suscitan algunos elementos propios del art. 1903 CC como el carácter de empresario mercantil de la entidad aseguradora, o que en este precepto estamos hablando de responsabilidad civil profesional y, por tanto, estamos dentro de las funciones encomendadas. Ahora bien, y esto es muy trascendente, resulta más que dudoso que el agente de seguros, que es per se un empresario mercantil, puede ser calificado de dependiente, tal y como ha sido definido en sede del art. 1903 CC, en especial si repasamos la jurisprudencia. Efectivamente, las sentencias relativas a la aplicación del art. 1903 Código civil permite ofrecer un catálogo de criterios cuya concurrencia o ausencia permiten, respectivamente, afirmar o negar la relación de dependencia. Así, habrá relación de dependencia y, por tanto, responsabilidad por hecho ajeno, cuando el principal ${ }^{19}$ :

- $\quad$ Regule el tiempo y lugar de trabajo, así como el de ocio y vacaciones.

- Se reserve las funciones de control, vigilancia o dirección de las labores encargadas.

- Ponga a disposición del dependiente los instrumentos y medios de trabajo necesarios.

- Asuma los riesgos económicos y financieros de la actividad.

Cualquiera de los criterios enunciados es suficiente para declarar la existencia de una relación de dependencia. Con frecuencia, la jurisprudencia española ha aplicado otros menos generales. Así, jueces y tribunales preguntan también sobre el modo de pago (mediante facturación o salario) de las labores encomendadas o quién es el titular de la póliza que cubre los daños causados a terceros por la actividad.

Pues bien, estos requisitos son precisamente antitéticos con la jurisprudencia consolidada en la jurisdicción de lo Social que se ha ocupado de deslindar la figura del agente de seguros frente a las meras relaciones laborales ${ }^{20}$. El agente debe ser un empresario mercantil independiente. En caso contrario, la jurisprudencia ha considerado que la relación debía considerarse como laboral y, por tanto, incompatible con la calificación de un contrato como de agencia, por lo que debe ser sustituido por un contrato laboral.

\footnotetext{
18 Seguimos aquí a Peña López, F. “Art. 1903 CC”, en AA.VV. (Dir. Bercovitz, R.), Comentarios al Código Civil, Tirant lo Blanch, 2013, pp. 13 y ss.

19 Sobre la cuestión AA.VV. (coord. Reglero Campos, F., Busto Lago, J.M.). Tratado de responsabilidad civil, $5^{\mathrm{a}}$ ed., Thomson Reuters Aranzadi, 2014.

20 Sobre la delimitación entre la relación mercantil o laboral puede consultarse, entre otras, la Sentencia núm. 1750/2019 de 11 junio Tribunal Superior de Justicia de C. Valenciana, (Sala de lo Social, Sección1ª). JUR $2019 \backslash 276104$.
} 
Sentado lo anterior, a nuestro juicio la imputación de la responsabilidad civil del agente de seguros a la aseguradora debiera calificarse de vicaria; lo que significa que, siendo responsable del daño el causante directo del mismo, cabe exigir responsabilidad también al asegurador, mas no por propia culpa, sino como garante del hecho de sus agentes de seguros y de la corrección de las actividades de su empresa.

\section{B. Una responsabilidad civil directa}

La siguiente pregunta a responder se centra en determinar si la responsabilidad civil del asegurador es directa y, por tanto, se puede ejercer por el cliente únicamente contra el asegurador o incluso acumularse en el mismo procedimiento la del asegurador y la del agente de seguros o es subsidiaria -lo que exige la previa reclamación al agente y solo ante la ausencia de satisfacción se podrá accionar contra el asegurador-.

El precepto, una vez más, dista de la precisión que una cuestión de tanto calado exige. La norma alude únicamente a que la responsabilidad será imputada, pero sin calificarla. Hubiera bastado añadir una mención a su carácter directo o subsidiario para disipar cualquier duda interpretativa. Ninguna precisión, empero, se ha hecho al respecto.

La jurisprudencia sobre el régimen anterior pudiera tener un carácter predictivo, pero lo bien cierto y verdad es que las resoluciones que han abordado la cuestión son casi inexistentes. Al respecto solo es dable mencionar la SAP Madrid núm. 91/2013 de 11 febrero de 2013 (Sección 12a), AC $2013 \backslash 472$ que al abordar un supuesto en que una entidad de crédito había distribuido como agente exclusivo un seguro unit link estableció la responsabilidad solidaria de ambas entidades, pero utilizando como argumento central de su razonamiento para la imputación del asegurador la apariencia de ser la misma $\cos ^{21}$.

${ }_{21}$ La sentencia estableció:

"Se discrepa por la representación del BANCO de la declaración de solidaridad que impone la sentencia. Se señala al respecto el carácter excepcional de la solidaridad frente a la mancomunidad, conforme al art. 1.138 del Código Civil, la inexistencia de relación contractual entre el BANCO y el demandante en la conclusión y desarrollo del contrato de seguro, y la incongruencia interna que supone imponer la restitución de la prestación a quien no fue contratante.

Sin embargo, la realidad acreditada funda sobradamente la responsabilidad de la entidad bancaria y, por ende, la condena solidaria junto con la aseguradora.

Desde un primer punto de vista, la misma apelante reconoce que actuó en la conclusión del contrato de seguro como agente exclusivo de BES VIDA (hecho primero, apartado 2.1 de la contestación de esta demandada y documento $\mathrm{n}^{\mathrm{o}} 2$ aportado con la misma).

Siendo esto así, le alcanza el primordial deber en relación al tomador, de ofrecer 'información veraz y

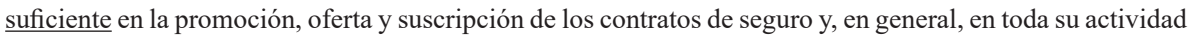
de asesoramiento' (art. 6 LMSRP).

Cuando, como en el caso, se trata de agente de seguro exclusivo, la responsabilidad se traslada a la aseguradora, según el art. 18 de la citada Ley (aplicable también a los operadores de banca-seguros -art. 25.1, último párrafo), pero ello es, según se cuida de señalar el referido art. 18, "sin perjuicio de la responsabilidad penal o de otra índole en que pudiera incurrir el agente de seguros exclusivo en el ejercicio de su actividad de mediación de seguros privados", e incurre en responsabilidad civil el agente, cuando infringe el deber establecido en el art. 6 LMSRP, que es justamente lo que en este proceso se ha evidenciado. Desde otro punto de vista, la estrecha relación entre las dos entidades, y sobre todo, la forma de actuar en la que únicamente era visible para el cliente, el propio BANCO, a través de su empleado de la Sucursal 
Por otro lado, la calificación de la responsabilidad civil como vicaria permite defender en este punto su carácter directo, si bien nada empece que pudiera ser también subsidiaria. Efectivamente, en nuestro ordenamiento jurídico una de las referencias a la hora de construir la responsabilidad civil vicaria es el art. 120 del Código penal, precepto que ha de incardinarse en sede de subsidiariedad. Sin embargo, en los ordenamientos en los que se impone la responsabilidad vicaria a los empresarios mercantiles, éstos responden directamente de los actos dañosos de sus dependientes, no siendo necesario demandar a éstos ni acreditar previamente su insolvencia. La posible exoneración del empresario vendrá, no cuando acredite su diligencia, sino cuando logre probar que no se dieron los elementos constitutivos de la responsabilidad ${ }^{22}$.

No obstante, la opción hermenéutica aquí defendida, hemos de reconocer que el precepto requerirá de una paulatina decantación jurisprudencial a medida que se vayan presentando supuestos de hecho que incidan sobre el régimen jurídico ahora analizado.

de Santander, según los datos fácticos que tiene en cuenta la Juez de Primera Instancia (último párrafo del fundamento de derecho primero de la sentencia apelada) datos que, en esa dimensión fáctica no son contradichos, da lugar a la vinculación del BANCO por aplicación de la doctrina de la apariencia.

Según expusimos, entre otras, en Sentencia de esta Sección de 24 de junio de 2.011 (JUR 2011, 320562), "conforme a esta doctrina, ínsita en el principio general de buena fe que proclama el art. 7.1 del Código Civil, aquel que, frente a un tercero, crea una situación que induce a éste a pensar racional, objetiva y fundadamente que se corresponde a la realidad, queda obligado frente a ese tercero, de la misma manera que si el hecho aparencial fuera verdadero.

Los requisitos para apreciar esa apariencia, con vinculación jurídica, serían los tres siguientes: $1^{\mathrm{a}}$ que el tercero haya actuado con la diligencia propia del negocio de que se trate, realizando, por su parte, los actos de constatación y averiguación que se muestren apropiados y proporcionados a las características de aquel negocio; $2^{\mathrm{a}}$ que esa apariencia haya sido inducida, mantenida o propiciada de algún modo por aquel a quien se reclama, y $3^{\mathrm{a}}$ que precisamente en base a esos actos - que tanto pueden ser activos como omisivos- el tercero haya consentido en contratar o en hacerlo del modo en que lo hizo. Tal doctrina obedece a ideas reiteradas por el Tribunal Supremo, cuya Sala 1ª declaró en Sentencia de 18 de marzo de 1999 (RJ 1999, 1858) que 'en el momento presente, pues, se protege firmemente la confianza en la apariencia', sosteniendo que "debe ser mantenido en su contrato quien lo celebró de buena fe con un representante aparente.

Esta vinculación que se da simplemente por la apariencia, mantenida, creada o inducida por el principal, se reitera en la Sentencias del Tribunal Supremo de 29 de octubre del 2.001, 2 de abril del 2.004 (RJ 2004, 2073) y 7 de noviembre del 2.005 (RJ 2005, 8186), entre otras.

La situación descrita en la sentencia, que asumimos plenamente, cae bajo esos expresados requisitos, pues fue el BANCO, a través de su empleado y sin hacer notorio el carácter de agente de seguros de la entidad, el que propuso el negocio, con una aseguradora que está incluida en su propio grupo y comparte incluso denominación (las siglas BES claramente se refieren a BANCO ESPIRTIRU SANTO), se utiliza indistintamente el logotipo de la aseguradora y del BANCO, y es éste y no la aseguradora el que dirige, siempre a través de su empleado, las comunicaciones sobre el estado de la inversión (documento $\mathrm{n}^{\circ} 8$ de la demanda). No se puede detectar ninguna negligencia o falta de diligencia en el demandante, cuando se trata de una situación mantenida y consolidada en el tiempo, y, finalmente, no es difícil inferir que fue la confianza en la actuación del propio BANCO la que determinó al demandante a contratar.

Finalmente, no hay inconsistencia o incoherencia alguna en imponer a quien no es contratante, pero sí es concurrente al acto incumplidor, la solidaridad en la obligación de restitución, cuando, como es el caso, es esencialmente fungible.

La solidaridad nace de la actuación conjunta, por no decir única, de las dos demandadas, de manera que a cualquiera indistintamente podría el perjudicado reclamar el total, y esta es precisamente la esencia de la solidaridad (arts. 1.137 y 1.144 del Código Civil)".

22 Zelaya Etchegaray, P. La responsabilidad civil del empresario por los daños causados por su dependiente, Aranzadi, 1995, p. 181. 


\section{El derecho de repetición del asegurador}

A nuestro juicio, menos dudas plantea la aplicación el art. 1904 CC que permite al asegurador que hubiera pagado la indemnización a la víctima, repetir lo satisfecho contra el agente de seguros que hubiera causado el daño. Como venimos defendiendo, el agente de seguros en cuanto empresario mercantil, es responsable civil de su actividad de distribución. Por tanto, si el asegurador se ve obligado a abonar alguna suma en aplicación del art. 143 RDLey $\mathrm{N}^{\circ} 3 / 2020$ nada empece a que se aplique el derecho de repetición contenido en el citado art. 1904 CC. Esta facultad presupone la responsabilidad de aquél contra quien se hace valer, impidiendo este derecho de repetición la impunidad de quien en definitiva debe responder de los daños, que no es otro que el agente de seguros.

\section{5. - El régimen aplicable a los operadores de banca-seguro}

Los operadores de banca-seguros quedan fuera del ámbito subjetivo de aplicación del precepto, sean exclusivos o vinculados. Aquí reside otra de las funciones del precepto: remitir a un régimen especial para los operadores de banca-seguros, que se contiene en el art. 152.1.g) RDLey $\mathrm{N}^{\circ} 3 / 2020^{23}$. De este modo los operadores de banca-seguros tienen la facultad de optar entre dos regímenes de responsabilidad:

a) Someterse al régimen de responsabilidad civil vicaria previa asunción por parte de todas las entidades aseguradoras de su responsabilidad civil profesional. En este caso, estimamos que nos situamos en un régimen similar al que acabamos de exponer con carácter general para el resto de agentes de seguro. No obstante, se aprecia una primera diferencia respecto del régimen anteriormente descrito. Efectivamente, cuando se trata de un agente de seguros exclusivo o vinculado la responsabilidad civil se impone al asegurador directamente por el legislador, aun cuando ya hemos manifestado nuestras dudas sobre si esto puede modificarse contractualmente. Por el contrario, la asunción de responsabilidad por parte de la aseguradora, aun en el caso de los operadores de banca-seguros exclusivos, es siempre consecuencia de una cláusula contractual del o de los contratos de agencia.

b) Asumir con carácter exclusivo la responsabilidad civil profesional, lo que implica la necesaria suscripción de un seguro de responsabilidad civil o de alguna garantía financiera que cubra las cantidades previstas por el legislador. Surge así otra diferencia respecto del régimen general aplicable a agentes exclusivos o vinculados, facultando al operador de banca-seguros a asimilar su responsabilidad profesional a la de los corre-

\footnotetext{
23 " $\mathrm{g}$ ) Acreditar que todas y cada una de las entidades aseguradoras con las que vaya a celebrar un contrato de agencia de seguros asumen la responsabilidad civil profesional derivada de su actuación como operador de banca-seguros, o que dicho operador dispone de un seguro de responsabilidad civil profesional o cualquier otra garantía financiera que cubra en todo el territorio de la Unión Europea las responsabilidades que pudieran surgir por negligencia profesional, de al menos 1.250.000 euros por siniestro y, en suma, 1.850.000 euros para todos los siniestros correspondientes a un determinado año, respecto a la actividad sobre la que no hubiera obtenido cobertura en virtud del contrato de agencia suscrito".
} 
dores. De este modo, su responsabilidad civil profesional será asumida solidariamente por el operador de banca-seguros y su asegurador de la responsabilidad civil o garante.

Este tratamiento diferenciado pudiera encontrar su fundamento en la solvencia que se presupone per se a los operadores de banca-seguros y en su mejor posición negociadora en el mercado frente a las aseguradoras. No obstante, estamos ante un tratamiento diferenciado, que es precisamente lo que ha querido evitar la DDS, debiéndonos cuestionar si es un privilegio que obtienen por esta vía las entidades de crédito o, por el contrario, una carga adicional ${ }^{24}$.

\section{IV.- LA LEGITIMACIÓN ACTIVA: LA NATURALEZA DE LA RESPONSABILIDAD CIVIL PROFESIONAL}

\section{1.- EL ASEGURADOR}

El agente de seguros se vincula con la o las entidades aseguradoras mediante un o unos contratos de agencia de seguros en los que rige la libertad de pactos, sin perjuicio de que se le pueda aplicar subsidiariamente la Ley de contrato de agencia (art. 141 RDLey $\mathrm{N}^{\circ}$ 3/2020). Por tanto, la responsabilidad civil profesional entre el asegurador y sus agentes se encauzará a través de los requisitos propios de la responsabilidad civil contractual que derive de las obligaciones estipuladas en los respectivos contratos y, en su caso, por el juego de la aplicación subsidiaria de la Ley de contrato de agencia, que no hay que desdeñar ante la parquedad de muchos de los documentos contractuales suscritos.

A partir de aquí, resulta complejo efectuar alguna nueva afirmación tan taxativa como la anterior, pues la concreta redacción de cada negocio jurídico puede variar bastante de un agente a otro. Sin ánimo de ser exhaustivo, poco tiene que ver el contrato suscrito por un agente en exclusiva persona física que comienza la actividad, con el firmado con un agente vinculado persona jurídica que cuenta con una cartera superior al millón de euros, por no mencionar el relativo a un operador de banca-seguros. Ni la posición negociadora, ni los intereses en juego, ni tan solo el conocimiento del sector son coincidentes en uno u otros casos. Si a esto añadimos otros factores como las diferentes políticas comerciales de cada aseguradora en sus redes de distribución o la carga que supone las funciones administrativas a desempeñar por el agente es fácil comprender que resulta natural el que aparezcan clausulados bien diferenciados.

Ahora bien, no podemos finalizar este epígrafe sin señalar que no toda relación obligatoria puede reconducirse al contenido propio del contrato de agencia. Baste señalar los arts. 136 y 142 RDLey $\mathrm{N}^{\circ}$, donde se califica la relación jurídica entre agente de

\footnotetext{
${ }^{24}$ Crítica por considerarlo una carga se muestra Rabanete Martínez, I., "El operador de banca-seguros", AA. VV (Dirs. Bataller Grau, J.; Quintáns Eiras, M.R). La distribución de los seguros privados, Marcial Pons, 2019, p. 316.
} 
seguros y aseguradora de contrato de depósito en lo relativo a las cantidades recibidas por el agente de seguros bien de la aseguradora bien del tomador.

En fin, el asegurador dilucidará la responsabilidad civil del agente de seguros usualmente por los cauces propios de la responsabilidad civil contractual, pero nada obsta a que pudieran existir supuestos de responsabilidad civil extracontractual cuando se supere el marco del contrato.

\section{2.- EL CLIENTE, EL TOMADOR Y EL ASEGURADO}

A nuestro juicio, la cuestión más controvertida dentro del presente trabajo será, probablemente, la relativa a la determinación de la naturaleza de la responsabilidad civil del agente de seguros por parte del cliente, del tomador o del asegurado.

Una primera aproximación desde la óptica de la teoría general del contrato de agencia nos llevaría a afirmar sin grandes complicaciones en sede dogmática que el único cauce posible sea el propio de la responsabilidad civil extracontractual. Efectivamente, si el agente de seguros se define por estar vinculado con el asegurador por un contrato de agencia y la Ley de contrato de agencia impone únicamente obligaciones al agente en favor del empresario principal (aquí la entidad aseguradora) - es más el agente ha de velar por los intereses del empresario principal-, el corolario de tal razonamiento es que las pretensiones del cliente frente al agente de seguros han de calificarse de responsabilidad civil extracontractual. Calificación que encuentra su sustento en la ausencia de vínculo contractual entre el agente y el cliente del empresario principal.

Sin embargo, esta conclusión debe ser revisada respecto del agente de seguros, lo que nos puede servir de ejemplo del modo en que la responsabilidad civil está cambiando de paradigma en el sistema financiero. El legislador está introduciendo regímenes jurídicos en la contratación de productos propios del mercado financiero que plantean alguna dificultad si intentamos reconducirla a los esquemas establecidos hasta la fecha bien para la responsabilidad civil contractual, bien para la extracontractual.

Un claro ejemplo de la evolución sufrida en esta materia es el asesoramiento que debe prestarse en la venta. Comencemos por su régimen jurídico en sede de distribución de seguros, para luego analizar las dudas que plantea su calificación como responsabilidad civil contractual o extracontractual.

\subsection{Información y asesoramiento en la distribución de seguros}

El RDLey $N^{\circ}$ 3/2020 en sede de distribución de seguros privados distingue entre la mera información y la labor de asesoramiento. El escrutinio de esta problemática debe partir del art.173 RDLey $\mathrm{N}^{\circ} 3 / 2020^{25}$, en relación con el art. 175 RDLey $\mathrm{N}^{\circ}$

\footnotetext{
25 "b) Si ofrece asesoramiento en relación con los productos de seguro comercializados. (....)

i) Por lo que se refiere al contrato ofrecido o sobre el cual se ha asesorado, si:
} 
$3 / 2020^{26}$, relativo a la información y asesoramiento previos a la contratación de un seguro, y los arts. 178 y ss. RDLey N 3/2020 sobre los denominados "productos de inversión basados en seguros".

Tras un análisis de la nueva regulación podemos diferenciar entre cuatro niveles en la actividad del distribuidor de seguros según la extensión de la labor exigible.

El primero nivel se corresponde con una actividad limitada a facilitar información. Ahora bien, no se trata de un suministro de datos aleatorio ni arbitrario. El distribuidor ha de partir de las informaciones obtenidas del cliente, las exigencias y las necesidades de dicho cliente para concretar la oferta. A partir de aquí, la labor del distribuidor se limita a proporcionar datos sin efectuar análisis de los mismos. Su función se restringe a que el tomador pueda formar una opinión fundada antes de aceptar la oferta (proposición) que se le haya planteado.

El siguiente eslabón es el asesoramiento en sentido estricto, que se produce cuando el distribuidor de seguros facilite al cliente una recomendación personalizada en la que explique por qué un producto concreto satisfará mejor las exigencias y necesidades del cliente ${ }^{27}$.

1. ${ }^{\circ}$ Facilita asesoramiento basándose en un análisis objetivo y personalizado;

$2 .^{\circ}$ está contractualmente obligado a realizar actividades de distribución de seguros exclusivamente con una, o, en su caso, autorizado con varias entidades aseguradoras, en cuyo caso deberá informar de los nombres de dichas entidades aseguradoras, o bien;

$3 .^{\circ}$ no está contractualmente obligado a realizar actividades de distribución de seguros exclusivamente con una o varias entidades aseguradoras y no facilita asesoramiento basándose en un análisis objetivo y personalizado, en cuyo caso deberá informar de los nombres de las entidades aseguradoras con las que pueda realizar, o de hecho realice, actividades de distribución de seguros del producto de seguro ofertado;

$4 .^{\circ}$ adicionalmente, en el caso de los operadores de banca-seguros, deberán comunicar a sus clientes que el asesoramiento prestado se facilita con la finalidad de contratar un seguro y no cualquier otro producto que pudiera comercializar la entidad de crédito o el establecimiento financiero de crédito".

26 "1. Antes de la celebración de un contrato de seguro, el distribuidor de seguros determinará, basándose en informaciones obtenidas del cliente, las exigencias y las necesidades de dicho cliente y facilitará al mismo información objetiva acerca del producto de seguro de forma comprensible, de modo que el cliente pueda tomar una decisión fundada.

Cualquier contrato que se proponga debe respetar las exigencias y necesidades del cliente en materia de seguros.

2. Si se facilita asesoramiento antes de la celebración de un contrato determinado, el distribuidor de seguros facilitará al cliente una recomendación personalizada en la que explique por qué un producto concreto satisfará mejor las exigencias y necesidades del cliente.

Cuando un mediador de seguros informe a su cliente de que facilita asesoramiento basado en un análisis objetivo y personalizado, deberá prestar ese asesoramiento sobre la base del análisis de un número suficiente de contratos de seguro ofrecidos en el mercado, de modo que pueda formular una recomendación personalizada, ateniéndose a criterios profesionales, respecto al contrato de seguro que sería adecuado a las necesidades del cliente.

3. Las precisiones a que se refieren los apartados 1 y 2 se modularán en función de la complejidad del producto de seguro propuesto y del tipo de cliente".

27 Sobre la venta asesorada, más ampliamente, Quintans EIRAS, R. "Información y conflicto de intereses en la comercialización de seguros", en AA.VV. (Dir. Girgado Perandones, P.). El contrato de seguro y su distribución en la encrucijada, Thomson Reuters Aranzadi, 2018, pp. 214 y ss.; PeÑas Moyano, M. J. "Obligaciones generales de información”, en AA. VV (Dirs. Bataller GraU, J.; Quintáns Eiras, M.R). La distribución de los seguros privados, Marcial Pons, 2019, p. 595; Girgado Perandones, P., "Obligaciones de información del mediador de seguros", en AA.VV. (Dir. Quintáns EIRAS, M.R). Estudios sobre Mediación de Seguros Privados, Thomson Reuters Aranzadi, 2013, p. 253. 
En este segundo estadio, por tanto, sí que hay un análisis de los contratos cuya conclusión conduce a efectuar una recomendación sobre el producto finalmente seleccionado.

Nada empece a que este asesoramiento se produzca por los agentes vinculados ni por los operadores de banca-seguros vinculados. La pluralidad de entidades con las que operan permite sin ningún género de dudas que el asesoramiento gire en torno a cuál es el producto más adecuado y qué asegurador pueda convenir más al cliente.

Más dudas puede plantear cuando se trate de un agente de seguros exclusivo u operador de banca-seguros exclusivo. El primer impulso puede hacernos descartar el asesoramiento dentro de la labor que desarrollan en el mercado con sus clientes ${ }^{28}$. A nuestro juicio, las posibilidades de asesoramiento son ciertamente más restringidas, pero no por ello quedan impedidas. Baste pensar en aquellos supuestos en que un asegurador tiene en su portafolio de productos varios tipos de contrato con diversas coberturas. La selección de uno y otro puede conllevar un asesoramiento en el sentido otorgado por el legislador.

Este estadio contiene una especialidad relativa a los operadores de banca-seguros. Cuando su labor pueda calificarse de asesoramiento han de añadir una cautela adicional: comunicar a sus clientes que el asesoramiento prestado se facilita con la finalidad de contratar un seguro y no cualquier otro producto que pudiera comercializar la entidad de crédito o el establecimiento financiero de crédito.

El tercer nivel se sitúa en el conocido como asesoramiento con análisis objetivo. A la anterior labor de asesoramiento se incluye tres nuevos requisitos: la independencia del distribuidor, el análisis de un suficiente número de productos, $\mathrm{y}$ el carácter personalizado de la recomendación. Más allá de las cuestiones que plantea este tercer nivel vamos a omitirlo del presente estudio, porque en la mente del legislador se encuentra reservado a los corredores.

Finalmente, el legislador ha previsto en los arts. 178 y ss. RDLey $N^{\circ}$ 3/2020 un régimen específico para los "productos de inversión basados en seguros"29. Los preceptos citados dedican varias normas en especial a la información previa, al asesoramiento que el agente de seguros facilita, en su caso, al cliente con relación a este tipo de productos de seguro. Se establece, en definitiva, un régimen reforzado de protección al

\footnotetext{
28 Así Quintans EIRAS, R. Información y conflicto de intereses, cit., 2018, p. 218 y, aunque refiriéndose a la Directiva Girgado Perandones, P. "Transparencia y deberes de información en la actividad profesional del mediador de seguros. A propósito de la nueva Directiva de Distribución de Seguros", La Ley Mercantil, $\mathrm{n}^{\circ}$ 21, enero, 2016 (versión digital sin paginar). A favor de extender el asesoramiento a todos los mediadores Díaz Llavona, C. "Borrador de la futura ley de distribución de seguros: más allá de la mera transposición de la directiva. Algunas valoraciones jurídicas iniciales”, Diario La Ley, nº 21, enero 2016 (versión digital sin paginar).

29 El RDLey N ${ }^{\circ}$ 3/2020 tiene como finalidad la transposición a nuestro ordenamiento de lo previsto en el Capítulo VI de la DDS. Estas disposiciones se complementan con otras normas comunitarias de directa aplicación entre las que destacan las normas técnicas de regulación contenidas en el Reglamento Delegado (UE) 2017/2359 de la Comisión de 21 de septiembre de 2017, por el que se completa la DDS en lo que respecta a los requisitos de información y las normas de conducta aplicables a la distribución de productos de inversión basados en seguros, dictado en virtud de la habilitación contenida en los arts. 28.4, 29.4 y 30.6 de la DDS para que la Comisión Europea adoptara actos delegados a fin de "concretar los criterios y los detalles prácticos para la aplicación de este conjunto de normas específico”.
} 
cliente que contrata uno de estos productos. Dicho régimen especial se superpone, sin sustituirlo, al régimen general, ya de por sí especialmente tuitivo, que la DDS implanta en la comercialización de todo tipo de $\operatorname{seguros}^{30}$.

Este régimen, además, es fundamentalmente equivalente al previsto para los productos de inversión minorista en la normativa MiFID II, configurada en torno a la Directiva 2014/65/UE del Parlamento Europeo y del Consejo, de 15 de mayo de 2014, relativa a los mercados de instrumentos financieros y por la que se modifican la Directiva 2002/92/CE y la Directiva 2011/61/UE.

\section{2. - Las dificultades de su calificación como responsabilidad civil extracontractual}

En primer lugar, la novedad de la regulación no supone ausencia de referencias. Los diferentes sectores que conforman el sistema financiero operan frecuentemente como vasos comunicantes. Por eso debemos acudir a la regulación del asesoramiento en otros ámbitos del sistema financiero y aquí tiene una especial virtualidad la jurisprudencia del Tribunal Supremo surgida con motivo de la colocación de participaciones preferentes y productos estructurados. Dentro de esta abundante jurisprudencia es dable encontrar resoluciones que han calificado el incumplimiento del deber de asesoramiento como contractual. Esta obligación, en ocasiones, debemos incardinarla en un previo contrato bancario, pero en otras muchas ocasiones, y esto es lo que ahora nos interesa destacar, se ha otorgado la misma calificación de contractual al asesoramiento prestado para la mera colocación de un producto creado por un tercero ajeno a la entidad de crédito que solo lo distribuye sin que concurriera contrato previo o simultáneo. Baste citar aquí las SSTS (Sala de lo Civil, Sección1 ${ }^{\text {a) }}$ n $^{\mathrm{o}}$ 379/2015 de 7 julio de 2015 (RJ 2015, 3914), la no 398/2015 de 10 julio de 2015 (RJ 2015/2776); y la no 397/2015 de 13 julio de 2015 (RJ 2015 2777$)^{31}$.

Asimismo, en el asesoramiento ofrecido por el agente de seguros podemos identificar todos los elementos propios de una obligación contractual. Por un lado, tenemos dos sujetos, uno en la posición deudora (el agente de seguros) y otro en la acreedora (cliente). No se trata pues de un deber impuesto con carácter general para preservar intereses generales, sino que es dable concretar el cumplimiento del asesoramiento respecto de cada uno de los clientes. Así pues, cuando abordamos la calificación desde

\footnotetext{
30 Más ampliamente DE LEÓN, F. "Obligaciones adicionales en relación con la distribución de productos de inversión basados en seguros", en AA. VV (Dirs. Bataller Grau, J.; Quintáns Eiras, M.R). La distribución de los seguros privados, Marcial Pons, 2019, pp. 605 y ss.; Gómez SANTos, M., "La distribución de los seguros unit-linked tras la Directiva de distribución de seguros y su normativa complementaria", en AA.VV. (Dir. Girgado Perandones, P.). El contrato de seguro y su distribución en la encrucijada, Thomson Reuters Aranzadi, 2018, pp. 275 y ss.

31 Sobre esta cuestión más ampliamente ver por todos Marimón DuRÁ, R. "Cambios en el mercado de crédito: nuevos operadores y nuevos modelos de negocio”, en AA.VV. (Dir. MARIMón DurÁ, R., Martí Miravalls, J.), Problemas actuales y recurrentes en los mercados financieros (Financiación alternativa, gestión de la información y protección del cliente), Thomson Reuters Aranzadi, 2018, pp. 88 y ss.
} 
la perspectiva de la legitimación parece que nos situamos más bien en el territorio de la responsabilidad civil contractual.

Por otro, la prestación en este caso es fácilmente definible -el asesoramiento sobre la solicitud formulada - pudiendo adjetivarse como lícita, posible y determinada. Lícita, porque la establece el mismo legislador. Posible pues a priori nada la impide, es más, el legislador al imponer unos especiales requisitos de formación al agente está coadyuvando a su diligente ejecución. En fin, la prestación es determinada pues es el legislador quien establece cual ha de ser su extensión en cada caso, como ya hemos descrito.

Correlato de lo expuesto es igualmente que la obligación se extingue atendiendo a los parámetros propios de la responsabilidad civil contractual.

A su vez, el art. 172.1 RDLey impone al distribuidor de seguros que actúen con honestidad, equidad y profesionalidad en beneficio de los intereses de sus clientes. Se produce, por tanto, un giro absoluto respecto al mandato del legislador en el art. 9.1 Ley de contrato de agencia donde la obligación del agente reside en velar por los intereses del empresario o empresarios por cuya cuenta actúe, sin que ningún otro interés deba ser tomado en consideración a la hora de valorar su conducta.

En fin, tampoco está de más traer a colación el art. 19 de la Ley de crédito inmobiliario donde el asesoramiento prestado por el intermediario es elevado por el mismo legislador a los altares de la categoría de contrato, siendo en este caso un negocio jurídico diferente del contrato de crédito.

\section{3. - Las dificultades de su calificación como responsabilidad civil contractual}

Sentado lo anterior, pudiéramos pensar que la respuesta a esta encrucijada consiste simplemente en determinar que su encaje es el propio de las relaciones contractuales. Ahora bien, aquí también es dable encontrar ciertas dificultades a la hora de incardinar la relación jurídica dentro de los elementos propios de las obligaciones contractuales.

En primer lugar, se trataría en el mejor de los casos de una obligación unilateral, pues el cliente no asume obligación alguna frente al agente de seguros. En el caso del agente de seguros, la retribución viene de la comisión o incluso cantidad fija que le abona la entidad aseguradora. Ninguna contraprestación asume el cliente frente al agente de seguros.

En esta línea, el cliente no presta consentimiento alguno a la prestación del asesoramiento que permita afirmar su naturaleza contractual. Obsérvese como en el art. 19 de la Ley de crédito inmobiliario se exige la suscripción de un contrato previo para la "previa determinación contractual del contenido, alcance y condiciones de éste". Por el contrario, en el asesoramiento previsto para el agente de seguros no se precisa esta concreción al estar ya previsto en el mismo RDLey $\mathrm{N}^{\circ} 3 / 2020$. Es más, no estimamos que sea lícito pactar una exoneración o limitación de responsabilidad, ni 
tan solo cuando el cliente no sea consumidor, dado el carácter imperativo que parece desprenderse de la norma.

En segundo lugar, aunque esta cuestión se nos plantea como más dudosa, no parece posible que el cliente pueda interponer una acción judicial para exigir el cumplimiento de la pretendida obligación de asesoramiento. Si el agente de seguros no efectúa el asesoramiento, tendrá consecuencias en sede de responsabilidad civil, pero no estimamos factible imponer el cumplimiento forzoso al agente de seguros.

Más allá de las dudas que plantea esta cuestión en sede de asesoramiento, no tenemos dudas que hay otros comportamientos impuestos al agente de seguros por el legislador que reciben la calificación de deber. Así sucede con el incumplimiento del deber de publicidad legal del agente (arts. 144 y 153 RDLey $N^{\circ} 3 / 2020$ ), del deber de transparencia sobre la retribución (art. 173 RDLey $\mathrm{N}^{\circ} 3 / 2020$ ) o del incumplimiento de las incompatibilidades (arts. 145 y 154.1 RDLey $\mathrm{N}^{\circ} 3 / 2020$ ). En ninguno de estos casos el cliente puede imponer el cumplimiento forzoso, elemento decisorio para la calificación de la obligación como contractual. Estamos pues ante meras cargas con trascendencia en sede de responsabilidad civil, pero cuyo cumplimiento no puede ser solicitado al juez de primera instancia.

En tercer lugar, el incumplimiento del deber de asesoramiento no permite la resolución de contrato alguno. Es más, en la jurisprudencia citada en sede de colocación de participaciones preferentes y productos estructurados se ha consolidado una doctrina jurisprudencial donde se afirma taxativamente que el incumplimiento del deber de asesoramiento no puede generar la resolución del contrato distribuido. Resulta cuanto menos complejo justificar la neutralidad respecto del contrato distribuido, si calificamos la obligación como contractual.

Finalmente, la imposición de una responsabilidad civil vicaria del asegurador en favor del cliente plantea menos problemas de definición si calificamos la responsabilidad civil del agente de seguros respecto del cliente de extracontractual.

\section{4. - Recapitulación crítica}

En las páginas precedentes no hemos pretendido excluir la existencia de responsabilidad civil extracontractual profesional en la relación entre cliente y agente de seguros. Nuestra intención es mucho más modesta y circunscrita a la previsión de los deberes previstos por el legislador en el RDLey $\mathrm{N}^{\circ} 3 / 2020$. Es aquí donde simplemente hemos querido reflejar las dudas que nos suscita reconducir el cumplimiento de los deberes de origen legal a las categorías propias de la responsabilidad civil contractual o extracontractual. Esta nueva forma de regular en el sistema financiero merece a nuestro modo de ver una reflexión intensa desde la perspectiva de la teoría general del Derecho privado para salvar las dificultades apuntadas. Solo tras un profundo análisis que excede de las pretensiones de este trabajo podrán dilucidarse los contornos de la responsabilidad civil del agente de seguros frente a sus clientes. 


\section{V.- LA CULPA}

La responsabilidad civil del agente, más allá de las dudas expuestas sobre su calificación como contractual o extracontractual, lo será por culpa. No parece que estemos ante un sistema de responsabilidad objetiva ${ }^{32}$.

Ahora bien, la especialidad en esta sede reside en que el parámetro de diligencia exigible al agente de seguros ha sido severamente elevado por el legislador a través de la imposición de múltiples deberes legales contenidos en el RDLey $\mathrm{N}^{\circ} 3 / 2020$. Sin poder entrar en su concreto análisis ni pretender ser exhaustivos, estos deberes pueden concretarse en:

a. las prohibiciones de los mediadores (art. 136.2 RDLey $\mathrm{N}^{\circ} 3 / 2020$ );

b. las incompatibilidades de los agentes (arts. 145 y 154.1 RDLey $\mathrm{N}^{\circ} 3 / 2020$ );

c. el deber de publicidad legal (arts. 144 y 153 RDLey $N^{\circ} 3 / 2020$ );

d. el incumplimiento de los requisitos de registro (art. 147 RDLey $\mathrm{N}^{\circ}$ 3/2020);

e. los principios rectores de la actividad del distribuidor (art. 172.1 RDLey $\mathrm{N}^{\circ}$ 3/2020);

f. los deberes de información y la labor de asesoramiento en la contratación de seguros (arts. 172, 173 y 175 RDLey $N^{\circ} 3 / 2020$ );

g. los deberes en sede de remuneración del agente (arts. 172 y 173 RDLey $\mathrm{N}^{\circ}$ $3 / 2020)$;

h. el deber de transmitir las comunicaciones (art. 146 RDLey $\mathrm{N}^{\circ}$ 3/2020);

i. $y$, en fin, los deberes adicionales en relación con la distribución de productos de inversión basados en seguros (arts. 178 y ss. RDLey N³/2020).

\section{VI.- EL DAÑo}

El daño se erige como un elemento central de la responsabilidad civil. En este epígrafe no aspiramos a extendernos en el debate sobre sus contornos, sino simplemente a señalar sus singularidades.

Circunscrito el ámbito de nuestro estudio, comenzaremos diciendo que sin pretender ser taxativos parece lógico pensar que los posibles daños generados por la actividad profesional del agente de seguros se limitarás usualmente a los patrimoniales, que como sabemos comprende tanto el daño emergente como el lucro cesante.

32 Elguero, J.M. La responsabilidad civil profesional ..., cit., p. 244. 
El daño emergente es el daño patrimonial directo y efectivo consistente en aquellos gastos realizados o que se van a realizar. En sede de responsabilidad civil del agente de seguros su cuantificación no será excesivamente compleja por lo general. El daño emergente se concretará en numerosas ocasiones bien en el valor de la prima, lo que se producirá cuando el tomador ha perdido la cuantía abonada a la aseguradora; o tras acaecer un siniestro en la diferencia entre una y otra indemnización.

El lucro cesante, por su parte, consiste en la ganancia dejada de obtener o la pérdida de ingresos. Desde el punto de vista teórico nada impide a que puedan exigírsele también al agente de seguros. Ahora bien, nos atrevemos a afirmar aquí que habrá pocos supuestos en la práctica en que concurran y además sea posible su prueba en sede judicial.

En definitiva, los daños exigibles al agente de seguros por el ejercicio de su actividad de distribución se rigen por los mismos parámetros que el resto de responsabilidad civil profesional. Ahora bien, en la práctica la pretensión del actor se ceñirá a los daños emergentes por ser los únicos que se puedan demostrar en el seno de un procedimiento judicial.

Aseveración que tampoco implica insinuar que la responsabilidad civil del agente de seguros sea una cuestión menor, ni mucho menos, pues las cantidades que alcance la cuantificación final de los daños puedan suponer cifras astronómicas. Baste pensar en aquellos supuestos en que la negligencia del agente de seguros ha supuesto la falta de cobertura de un siniestro de importantes dimensiones.

\section{VII.- EL NEXO DE CAUSALIDAD}

Finalmente, la doctrina exige la concurrencia de un nexo de causalidad para la imposición de una responsabilidad civil a quien haya generado un daño. Éste elemento trata de dilucidar si la conducta del sujeto eventualmente responsable tuvo la suficiente entidad como para provocar el daño y, a su vez, determinar si todos los daños que hayan acontecido son imputables al citado sujeto.

En esta sede, a nuestro juicio, no concurre ninguna singularidad respecto de la responsabilidad civil del agente por su actividad de distribución. Se aplicaran aquí sin más las habituales disquisiciones entre causalidad física y causalidad jurídica desarrolladas por la dogmática civilista Así las cosas deberemos acudir a la teoría general sobre el nexo de causalidad sin que concurran singularidades que deben ser reseñadas.

\section{VIII.- LA DESCONCERTANTE DISPOSICIÓN TRANSITORIA $3^{a}$ DEL RDLEY $N^{\circ} 3 / 2020$}

La plena conformación del régimen requiere acudir, finalmente, a la disposición transitoria tercera, que establece que los agentes vinculados y operadores de banca seguros -no así los agentes exclusivos- cuando estén inscritos en el registro administrativo de mediadores de seguros antes de la entrada en vigor del RDLey $\mathrm{N}^{\circ} 3 / 2020$-esto es 
el 5 de febrero de 2020- se regirán bajo el mismo régimen de responsabilidad civil profesional previsto para aquellos en la LMSRP.

Una interpretación literal ${ }^{33}$ de la norma nos conduciría a la existencia de siete-sí, siete-regímenes de responsabilidad civil profesional del agente de seguros diferentes en función de su clase y de su fecha de inscripción en el registro. Las variables indicadas producen los siguientes regímenes:

$1^{\circ}$ ) Los agentes de seguros exclusivos, con independencia de la fecha de inscripción en el registro, estarían sometidos plenamente al RDLey $\mathrm{N}^{\circ} 3 / 2020$.

$2^{\circ}$ ) Los agentes de seguros vinculados ya inscritos con al LMSRP estarían regulados por la LMSRP.

$3^{\circ}$ ) Los agentes de seguro vinculados no inscritos vigente la LMSRP actualmente estarían bajo el imperio del RDLey $\mathrm{N}^{\circ}$ 3/2020.

$4^{\circ}$ ) Los operadores de banca-seguros exclusivos inscritos con al LMSRP estarían regulados por la LMSRP, donde recordemos estaban sometidos en este punto al régimen general de agentes exclusivos sin hacer distingos entre unos y otros.

$5^{\circ}$ ) Los operadores de banca-seguros exclusivos no inscritos vigente la LMSRP entrarían dentro del ámbito de aplicación del RDLey $\mathrm{N}^{\circ}$ 3/2020.

$6^{\circ}$ ) Los operadores de banca-seguros vinculados inscritos se regirían por la LMSRP

$7^{\circ}$ ) Los operadores de banca-seguros vinculados no inscritos, en fin, se acogerían al régimen del RDLey $\mathrm{N}^{\circ}$ 3/2020.

Pocas veces en el ordenamiento jurídico español se han dado supuestos en que un mismo empresario mercantil, el agente de seguros, pudiera estar sometido hasta siete regímenes jurídicos de responsabilidad civil profesional diferenciados.

Expuesta las consecuencias de una posible interpretación literal de la norma, en primer lugar, convendremos que someter a unos empresarios mercantiles a un régimen de responsabilidad civil diferente según la fecha de inscripción en un registro administrativo plantea cuanto menos alguna objeción de entrada. Efectivamente, conceder un régimen más beneficioso en el ejercicio de su actividad en el mercado a unos mediadores sobre otros altera el regular juego de la competencia ${ }^{34}$. Resulta fácil entender que quien soporta menos responsabilidad civil es siempre más competitivo, pues su actuación en el mercado acarrea un menor coste, lo que le permite, además, ser más agresivo en sus prácticas.

Así pues, resulta difícil justificar las razones que subyacen para tal diferenciación más allá de imponer una barrera de entrada a nuevos operadores en beneficio de los

\footnotetext{
33 Acogen una interpretación literal de la norma Elguero, J.M. La responsabilidad civil profesional..., cit., p. 249; RABANETE MARTíneZ, I. El operador de banca-seguros ..., cit, 2019, p. 316.

34 En este sentido, aunque con consecuencias diversas a las que defendemos, ElguERo, J.M. La responsabilidad civil profesional ..., cit., p. 249.
} 
existentes. A lo que hay que añadir que la principal línea rectora de la DDS es precisamente proporcionar a todos los consumidores el mismo nivel de protección a pesar de las diferencias entre los canales de distribución, por ello es fundamental que haya unas condiciones de competencia equitativas entre los distintos distribuidores.

Dando un paso más, la interpretación literal de la norma plantea severas objeciones si nos detenemos en su ámbito de aplicación. Su tenor alude al régimen de responsabilidad civil profesional sin limitación alguna. Y como hemos visto la responsabilidad civil profesional del agente de seguros se encuentra fuertemente modalizada por la introducción de deberes legales que el agente de seguros debe atender inexcusablemente y cuyo incumplimiento son su principal fuente de responsabilidad civil profesional. Carece de sentido que el agente de seguros venga obligado al cumplimiento de los deberes legales del RDLey $N^{\circ} 3 / 2020$, pero seguidamente su responsabilidad civil dependiera exclusivamente del menor rigor que en el desempeño de su actividad imponía la LMSRP. Deberes vigentes que provienen en gran medida de la misma DDS que se traspone mediante el RDLey $\mathrm{N}^{\circ} 3 / 2020$.

Tras lo expuesto, nos atrevemos a afirmar que una interpretación literal de la norma sería contraria al Derecho comunitario, por lo que es necesario adecuarla a los mandatos de la DDS en aras a lograr una interpretación conforme a sus preceptos.

Esta tesis encuentra un nuevo argumento en la propia Disposición derogatoria del RDLey $N^{\circ}$ 3/2020. La norma declara expresamente derogada la LMSRP sin imponer limitación alguna. Por tanto, parece reforzar la tesis que la Disposición transitoria no supone el establecimiento sine die de un régimen de responsabilidad civil profesional diferente, pues hubiera requerido apuntillar su tenor literal imponiendo la salvedad de la vigencia de la LMSRP en este ámbito.

Llegado a este punto debemos ofrecer una interpretación alternativa que desde nuestra modesta opinión debe partir de su ubicación sistemática que no es otra que prever un régimen transitorio para clarificar el tránsito de un sistema registral a otro. Con estas coordenadas, estimamos que la interpretación más razonable reside en entender que lo que se ha querido es exonerar a los agentes vinculados y a los operadores de banca seguros de efectuar una nueva manifestación en el registro administrativo sobre la opción entre asunción de responsabilidad por el asegurador o por la suscripción de un seguro de responsabilidad civil propio.

Ahora bien, las dudas surgen en la extensión de tal interpretación cuando se traté de un agente vinculado, pues como hemos visto en el régimen vigente no admite la posibilidad de suscribir un seguro de responsabilidad civil. Opción por el seguro que sí admitía la LMSRP y es conforme con el art. $10 \mathrm{DDS}^{35}$.

\footnotetext{
35 Los intermediarios de seguros y reaseguros deberán disponer de un seguro de responsabilidad civil profesional que cubra todo el territorio de la Unión, o de cualquier otra garantía comparable para las responsabilidades que pudieran surgir por negligencia profesional, de al menos 1250000 EUR por siniestro y, en total, 1850000 EUR para todos los siniestros correspondientes a un determinado año, a menos que tal seguro o garantía comparable ya esté cubierto por la empresa de seguros o reaseguros u otra empresa en
} 
A nuestro juicio, debe prevalecer una interpretación restrictiva limitando la pervivencia de la declaración en el registro administrativo, tanto en cuanto sea compatible con el régimen de responsabilidad civil profesional vigente en el RDLey $\mathrm{N}^{\circ} 3 / 2020$. Así lo impone, según nuestro criterio, la necesidad de someter a todos los distribuidores a condiciones equivalentes.

\section{BIBLIOGRAFÍA}

AA.VV. La responsabilidad en el Derecho, AFDUAM n ${ }^{\circ}$ 4, 2000.

AA.VV. (Dir. Bercovitz, R.). Comentarios al Código Civil, Thomson Reuters Aranzadi, 2001.

AA.VV. (coord. Cuñat Edo, V.; Bataller Grau, J.). Comentarios a la Ley de Mediación de Seguros y Reaseguros Privados, Thomson Reuters Civitas, 2007.

AA.VV. (Dir. Bercovitz, R.). Comentarios al Código Civil, Tirant lo Blanch, 2013.

AA.VV. (Dir. Quintáns EIRAs, M.R). Estudios sobre Mediación de Seguros Privados, Thomson Reuters Aranzadi, 2013.

AA.VV. (Dirs. Bataller Grau, J; Veiga Copo, A.). La protección del cliente del mercado asegurador, Thomson Reuters Civitas, 2014.

AA.VV. (coord. Reglero Campos, F., Busto Lago, J.M.). Tratado de responsabilidad civil, $5^{\text {a }}$ ed., Thomson Reuters Aranzadi, 2014.

AA.VV. (Dirs. Bataller Grau, J; Quintáns Eiras, M.R.; Veiga Copo, A.). La reforma del Derecho del seguro, Thomson Reuters Aranzadi, 2016.

AA.VV. (Dirs. Bataller Grau, J; Peñas Moyano, M.J.). Un Derecho del seguro más social y transparente, Thomson Reuters Aranzadi, 2017.

AA.VV. (Dir. Girgado Perandones, P.). El contrato de seguro y su distribución en la encrucijada, Thomson Reuters Aranzadi, 2018.

AA.VV. (Dir. Marimón Durá, R., Martí Miravalls, J.). Problemas actuales y recurrentes en los mercados financieros (Financiación alternativa, gestión de la información y protección del cliente), Thomson Reuters Aranzadi, 2018.

AA. VV (Dirs. Bataller Grau, J.; Quintáns Eiras, M.R). La distribución de los seguros privados, Marcial Pons, 2019.

Atienza Navarro, M.L. "La responsabilidad civil”, en Estudios de derecho judicial, (Ejemplar dedicado a: La responsabilidad personal del juez), nº 153, 2008, pp. 127 y ss.

De Ángel YÁgüEz, R. Tratado de Responsabilidad Civil, Civitas, 1993.

cuyo nombre actúe el intermediario de seguros o de reaseguros, o por la cual el intermediario de seguros o de reaseguros esté facultado para actuar, o la empresa en cuestión asuma plena responsabilidad por los actos del intermediario. 
DíAz Llavona, C. "Borrador de la futura ley de distribución de seguros: más allá de la mera transposición de la directiva. Algunas valoraciones jurídicas iniciales", Diario La Ley, $\mathrm{n}^{\circ}$ 21, enero 2016 (versión digital sin paginar).

Díez-Picazo, L. Derecho de daños, Madrid, Civitas, 2000.

Gasco Ortiz, A. "Obligaciones de información y normas de conducta en el borrador de Anteproyecto de la Ley de distribución de seguros y reaseguros privados», La Ley Mercantil, $\mathrm{n}^{\circ}$ 46, abril, 2018 (versión digital sin paginar).

Girgado Perandones, P., “Transparencia y deberes de información en la actividad profesional del mediador de seguros. A propósito de la nueva Directiva de Distribución de Seguros", La Ley Mercantil, n 21, enero, 2016 (versión digital sin paginar).

Muñoz Paredes, J. M. a "La responsabilidad de los distribuidores en el Anteproyecto de Ley de Distribución", Revista Española de Seguros, n 171-172, 2017, pp. 361 y ss.

Pantaleón Prieto, F., en AA.VV. Comentario al Código Civil, II, Ministerio de Justicia, 1991, pp. 1971 y ss.

Quintáns Eiras, M.R. "De la mediación a la distribución de seguros. La nueva Directiva 2016/1997”, Revista General de Derecho Europeo, n. 39, 2016.

- "Información como motor de la protección del asegurado en la comercialización de seguros", Revista Española de Seguros, $\mathrm{n}^{\circ}$ 175, 2018, pp. 373 y ss.

Serra Rodríguez, A. La responsabilidad civil del abogado, Thomson Reuters Aranzadi, 2000.

TiRAdo SuÁRez, F.J. Comentarios a la nueva ley de mediación en seguros privados, CES, Madrid, 1992.

Tirado Suárez, F.J./Sarti Martínez, M.A. Ley de Mediación en Seguros y Reaseguros Privados, Thomson Reuters Aranzadi, 2007.

Veiga Copo, A. Tratado del contrato de seguro, $6^{\text {a }}$ ed., Thomson Reuters Civitas, Madrid, 2019.

YzQuierdo TolsADA, M. Responsabilidad civil extracontractual.: delimitación y especies, elementos, efectos o consecuencias, 5 ed., Dykinson, 2019.

Zelaya Etchegaray, P. La responsabilidad civil del empresario por los daños causados por su dependiente, Aranzadi, 1995. 